\title{
Influence of High Water Pressure on Static and Dynamic Compressive Strength of Concrete
}

\author{
Jikai Zhou (D), Xiyao Zhao $\left(\mathbb{D}\right.$, Yu Nie $\mathbb{D}^{D}$, and Yun Tian $(\mathbb{D}$ \\ College of Civil and Transportation Engineering, Hohai University, Nanjing 210024, China \\ Correspondence should be addressed to Jikai Zhou; zhoujikaihhu@hotmail.com
}

Received 15 April 2020; Revised 1 June 2020; Accepted 4 June 2020; Published 29 June 2020

Academic Editor: Andreas Lampropoulos

Copyright (@) 2020 Jikai Zhou et al. This is an open access article distributed under the Creative Commons Attribution License, which permits unrestricted use, distribution, and reproduction in any medium, provided the original work is properly cited.

\begin{abstract}
In this paper, an experimental study was conducted on the influence of water pressure on concrete strength. Specimens were put in a self-designed device, applying 0-4 MPa water pressure on concrete, and then taken out for both static and dynamic compressive tests. Results showed that high water pressure caused inevitable damage to concrete, leading to $13.4 \%$ reduction in strength under $4 \mathrm{MPa}$ water pressure. Specimens with lower strength grade were damaged more severely while under the same water pressure. Also, as water pressure increased, the moisture content of concrete grew linearly, and the trend for specimens with higher compressive strength was slower. A correlation was established between the water content increment and the reduction rate of strength. Moreover, the dynamic compressive strength decreased as water pressure increased but still higher than the static strength, illustrating an apparent strain rate effect. Meanwhile, water pressure and moisture content increment barely had any influence upon DIF within the testing conditions. Furthermore, equations for calculating both static and dynamic reduction rates of strength were built, based either on water pressure or on moisture content increment caused by that. Equations for strength prediction were also provided.
\end{abstract}

\section{Introduction}

A series of $300 \mathrm{~m}$ high arch dams have been constructed in the high seismic areas among Midwest China, such as Xiaowan Arch Dam (292 m), Jinping-I Arch Dam (305 m), Xiluodu Project (278 m), and Baihetan Arch Dam (289 m), and more will be constructed [1]. The water pressure on dam concrete approaches to $3 \mathrm{MPa}$. Since concrete is considered a porous material, whether high water pressure would deteriorate its static and dynamic mechanical properties requires further investigation $[2,3]$.

Scholars mainly focus on the effect of moisture content on mechanical properties of concrete, in which specimens were not put under water pressure. It has been generally believed that the static strength of concrete declines with increasing water content [4-7]. The strain rate effect of wet concrete was found to be apparent when the loading rate was between $0.5 / \mathrm{s}$ and 1.25/s [8]. According to Ross [9], the accumulation of moisture content would increase the rate sensitivity and dynamic compressive strength of concrete under the strain rate of $1 / \mathrm{s}-10 / \mathrm{s}$. Similar results were obtained under the strain rate of $10^{-6} / \mathrm{s}-10^{-3} / \mathrm{s}$ by $\mathrm{Wu}$ et al. [10]. When the strain rate was as high as $100 /$ s, higher water content would also lead to lower compressive strength. The dynamic compressive strength of saturated specimens held $77 \%$ of that of dry ones [11].

Reinhardt et al. [8] concluded based on tests that when the loading rate was between $0.5 / \mathrm{s}$ and $1.25 / \mathrm{s}$, the strain rate effect of wet concrete was apparent. Ross et al. [9] studied that under impact loading $(1 / \mathrm{s}$ and $10 / \mathrm{s})$, the tensile strength of concrete grew obviously with the accretion of relative humidity. Wu et al. [10] experimented under a high loading rate of $100 / \mathrm{s}$, with the conclusion that higher the water content, lower the compressive strength. The dynamic compressive strength of fully saturated specimen held $77 \%$ of that of dry ones. According to Bartlett and MacGregor [5], the accumulation of moisture content would enhance the rate sensitivity of concrete, and dynamic compressive strength raised along with moisture content under a strain rate of $1 / \mathrm{s}-10 / \mathrm{s}$. Zhou et al. [11] carried out tests under a 
loading rate in the range of $10^{-6} / \mathrm{s}-10^{-3} / \mathrm{s}$, and the outcome also confirmed that point of view.

A few experimental pieces of research involved the influence of water pressure on the compressive strength of concrete. Clayton [12] summarized based on tests that after being subjected to $60 \mathrm{MPa}$ water pressure for six days, the compressive strength and flexural strength of concrete decreased $12 \%$ and $50 \%$, respectively. $\mathrm{Li}$ and $\mathrm{Du}$ [13] experimented on the effect of water pressure, in the range of $0-2.5 \mathrm{MPa}$, on mechanical properties of concrete. As water pressure increased, the static compressive strength, tensile strength, and elastic modulus decreased gradually, with a strength degradation of $32.6 \%$ at maximum. Wang et al. [14] also reported the nonlinear decrease of static compressive strength when water pressure increased from 0 to $10 \mathrm{MPa}$. Results of Van Der Wegen et al. [15] illustrated that almost no negative impact had high water pressure $(10 \mathrm{MPa})$ on concrete strength. Bjerkeli et al. [16] conducted experiments with a testing condition of $8 \mathrm{MPa}$ water pressure, with an opinion that water pressure barely had substantial ramifications on static compressive strength. A unified theory could not be formalized based on the few test results mentioned above yet. It is necessary to carry out further experimental research on the influence of water pressure on static and dynamic compressive strength of concrete.

Several mechanisms explaining the effect of water content on strength have been raised. Butler [17] was in support that water flow driven by the difference between the internal and external water pressure led to active pore water pressure. This caused tensile stress, local splitting formation, and eventually strength degradation. Bary et al. [18] analyzed the effect of pore water pressure by coupling external mechanical loading and pore water. Rossi [19] and Zheng and $\mathrm{Li}[20]$ explained the increase of strength under impact loading based on Stefan effect that the cohesive stress induced by water in cracks inhibited the growth of cracks. According to Oshita and Tanabe [21], the volume strain of concrete was the most significant factor affecting pore water pressure, and the pore pressure accelerated crack development. Shen and Xu [22] were in favor that the increase of porosity enhanced the impact of moisture content on strength, proposing a strength-porosity-saturation model based on the Ryshkewitch [23] model. By molecular dynamics simulation, Zhou and Liang [24] concluded that due to water molecular entering the $\mathrm{C}-\mathrm{S}-\mathrm{H}$ structure, the interatomic distance was entrenched, and atomic interactions were weakened. This resulted in the degradation of overall tensile properties. Also, the increment of moisture content enhanced the sensitivity of tensile strength.

The present paper aims at the engineering safety evaluation of 300-meter high arch dams. The static and dynamic compressive strength of concrete under 0-4 MPa water pressure was investigated experimentally, and their changing pattern was analyzed. An interpretation of the underlying mechanism of these changes was provided.

\section{Materials and Methods}

2.1. Experimental Devices. A set of high water pressure device was designed in order to study the effect of water pressure on concrete, as illustrated in Figure 1. The maximum working pressure was $4 \mathrm{MPa}$, for simulating $400 \mathrm{~m}$ water depth at maximum. The testing apparatus contained two parts, a pressure pump and a primary pressure-maintaining device. The latter consisted of several components: an internal pressure-maintaining chamber, a safety valve, a water inlet valve, a water outlet valve, and an exhaust valve. Components were connected by flanges and sealing rings to ensure the tightness of the whole apparatus. The effect space of the internal chamber is $\Phi 500 \mathrm{~mm} \times 400 \mathrm{~m}$, both inside and outside of which were coated with anticorrosive painting. In the working state, the device needed to be slightly repressurized every 24 hours for maintaining the pressure.

Previous research has demonstrated that after being immersed in pressurized water (more than $1 \mathrm{MPa}$ ) for 48 hours, the water content of concrete tends to be stable [14]. In the present study, the water pressure was maintained for 96 hours, so water could permeate into specimens sufficiently. After being pressurized for the required length of testing time, specimens were taken out of the device and put into clean water for curing. After the difference between internal and external pressure of the specimens dissipated, they were taken out and surfaces of which were dried. All specimens were put in the laboratory for 3 hours before further tests.

The static and dynamic compression tests were carried out afterward. The electrohydraulic servo compression test machine was applied in the static tests, while the dynamic tests were conducted with the Split-Hopkinson Pressure Bar (SHPB). The ending faces of specimens were polished smoothly. However, faces of specimens were found not parallel with the compression bar perfectly, which might result in uneven stress distribution during impact loading. A universal head was employed to ensure that the specimen fits the pressure bar well, reducing the influence of the uneven fitness on test results.

2.2. Specimens. In the experiments, the 42.5 ordinary Portland cement was used as the cementitious materials. 0.4-2.5 continuous graded medium sand was used as the fine aggregate, and gravel with the maximum particle size of $15 \mathrm{~mm}$ was used as the coarse aggregate. The water-reducing agent applied was the polycarboxylic acid superplasticizer. The $\mathrm{w} / \mathrm{c}$ was 0.38 , and the concrete mixture ratio by weight is listed in Table 1. The mixture and procedure of making specimens were designed according to GB175-2009, Common Portland Cement, a Chinese testing standard [25]. Specimens were casted in cylindrical PVC molds with an external diameter of $75 \mathrm{~mm}$. The mixture was poured into molds, vibrated and compacted twice. Specimens were removed from the molds after 24 hours and then cured in water for 28 days. Both ends of the specimens were sliced off with the numerical control cutting machine. The cut surfaces 


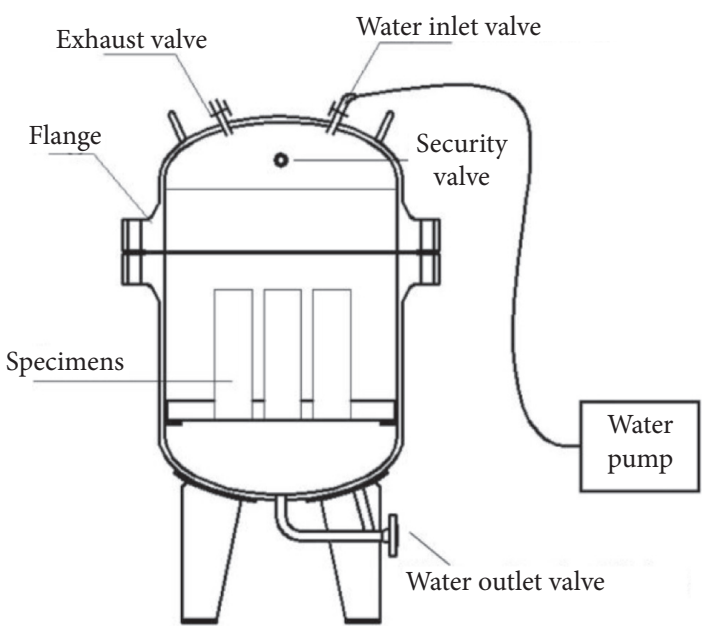

FIGURE 1: High water pressure device.

TABle 1: Concrete mixture ratio by weight.

\begin{tabular}{lccccc}
\hline & \multicolumn{2}{c}{ Concrete compositions $\left(\mathrm{kg} / \mathrm{m}^{3}\right)$} & \multicolumn{2}{c}{ Superplasticizer } \\
Water & Cement & Fine aggregate & Coarse aggregate & w/c ratio \\
\hline 180 & 474 & 668 & 1089 & 3.80 & 0.38 \\
\hline
\end{tabular}

were polished to keep them smooth and complete. Eventually, the specimens were cut into cylinders with a height of $147 \mathrm{~mm}$, and discs with a height of $37 \mathrm{~mm}$. Since specimens were tested after more than 180 days, one could ignore the influence of age on concrete strength.

2.3. Test Conditions. First, specimens were put into the water pressure simulation device, subjected to different levels of water pressure for 96 hours. Regarding the applied water pressure $(0,1,2$, and $4 \mathrm{MPa})$, specimens were divided into four groups, namely A, B, C, and D. After this, static compression tests were conducted on cylinder specimens (A0-D0) and disc specimens (A1-D1). Dynamic compression tests were conducted on disc specimens (A2-D2). Group numbers of specimens are listed in Table 2. The load in the static test was applied at the rate of $0.5 \mathrm{MPa} / \mathrm{s}$. The loading rate in dynamic test was determined by impact pressure, which was set to $0.7 \mathrm{MPa}$. Three specimens were tested under each condition, in a total of 36 of the whole research. Moreover, the moisture content of specimen subjected to different water pressure was measured. For specimens taken out of the water pressure device, mass of each was measured both before and after drying at $60^{\circ} \mathrm{C}$ for 48 hours. The gap between two measurements relative to the value before drying was defined as the moisture content. All test procedures were set according to $D L / T$ 5150-2001, Teat Code for Hydraulic Concrete [26].

\section{Results and Discussion}

3.1. Failure Pattern. The failure pattern of specimens in the SHPB test is presented in Figures 2(a)-2(d). When the
TABLE 2: Group numbers of specimens.

\begin{tabular}{lccc}
\hline \multirow{2}{*}{ Water pressure $(\mathrm{MPa})$} & \multicolumn{2}{c}{ Static test } & \multirow{2}{*}{ Dynamic test } \\
& Cylinder & Disc & \\
\hline 0 & A0 & A1 & A2 \\
1 & B0 & B1 & B2 \\
2 & C0 & C1 & C2 \\
4 & D0 & D1 & D2 \\
\hline
\end{tabular}

impact pressure was $0.7 \mathrm{MPa}$, the fracture of specimens was relatively complete. As the time of the SHPB test was very short, the energy inside specimens needed to be released rapidly, so cracks could only develop along with the interface between coarse aggregates and concrete matrix. Specimens broke into fragments of nearly equal size. Specimens subjected to higher water pressure before tests broke into pieces more uniform in size and had fewer large fragments.

The failure pattern of the cylindrical specimens in static compression test is shown in Figures 2(e)-2(h). One single or several vertical through cracks exist in the damaged specimens. This demonstrated a combination of split and shear failure. However, little difference could be observed among the cylinder specimens processed by different water pressure in static tests.

\subsection{Static Compressive Strength of Concrete Subject to Water} Pressure. The static compressive strength of specimens under different water pressure was obtained by experiments, as demonstrated in Table 3. It could be summarized that with the increase of water pressure, the strength of cylinder specimens illustrated an overall downward trend. While the reduction rate of strength increased. When the water 


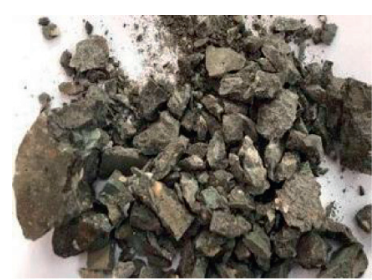

(a)

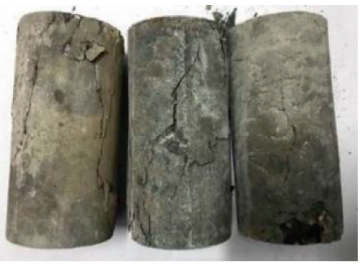

(e)

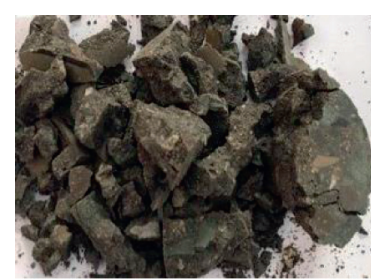

(b)

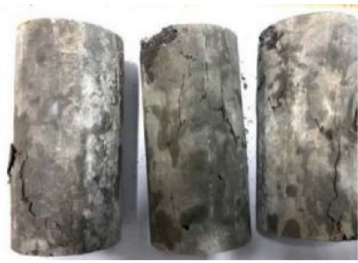

(f)

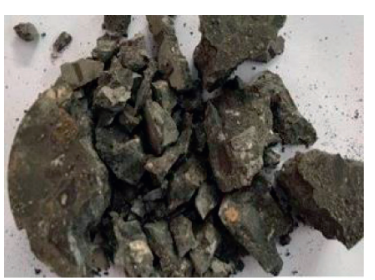

(c)

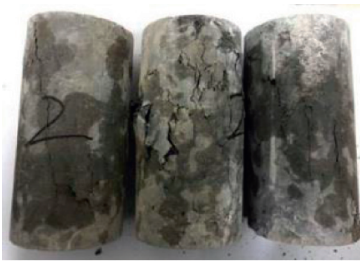

(g)

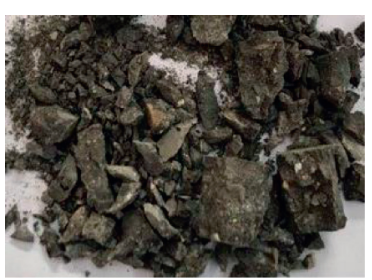

(d)

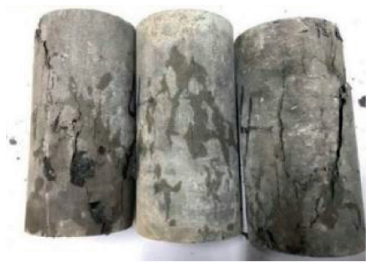

(h)

FIGURE 2: Failure mode of specimens under different water pressure. (a-d) Dynamic loading under $0 \mathrm{MPa}, 1 \mathrm{MPa}, 2 \mathrm{MPa}$, and $4 \mathrm{MPa}$ water pressure; (e-h) static loading under $0 \mathrm{MPa}, 1 \mathrm{MPa}, 2 \mathrm{MPa}$, and $4 \mathrm{MPa}$ water pressure, respectively.

TABLE 3: Static compressive strength of concrete under different water pressure/MPa (cylindrical specimens).

\begin{tabular}{|c|c|c|c|c|c|c|}
\hline Serial number & Water pressure & Specimen 1 & Specimen 2 & Specimen 3 & Average & $D_{\mathrm{s}}$ \\
\hline$\overline{\mathrm{A} 0}$ & 0 & 45.04 & 45.97 & 43.88 & 44.96 & 0 \\
\hline B0 & 1 & 41.25 & 40.75 & 43.04 & 41.68 & $7.3 \%$ \\
\hline $\mathrm{C} 0$ & 2 & 43.27 & 44.73 & 43.50 & 43.82 & $2.5 \%$ \\
\hline D0 & 4 & 38.34 & 37.21 & 41.27 & 38.94 & $13.4 \%$ \\
\hline
\end{tabular}

pressure increased from $0 \mathrm{MPa}$ to $1 \mathrm{MPa}, 2 \mathrm{MPa}$, and $4 \mathrm{MPa}$, the average reduction rate of compressive strength was $7.3 \%$, $2.5 \%$, and $13.4 \%$, respectively.

Disc specimens exhibited the same characteristic as cylinders. There was a linearly decreasing relationship between static strength and water pressure, as shown in $\mathrm{Ta}-$ ble 4. Due to the size effect and confinement effect, the static strength of disc specimens was significantly higher than that of the cylinders. When the water pressure rose from $0 \mathrm{MPa}$ to $1 \mathrm{MPa}, 2 \mathrm{MPa}$, and $4 \mathrm{MPa}$, the average reduction rate of compressive strength was $7.1 \%, 4.4 \%$, and $11.8 \%$, in respective. The strength of specimens subjected to $4 \mathrm{MPa}$ water pressure decreased by about $12 \%$, no matter the size. Therefore, the ratio of diameter to height has little influence on the reduction rate of strength.

The correlation between water pressure and the reduction rate of strength studied in this paper is depicted in Figure 3. It could be found that in the range of $0-4 \mathrm{MPa}$ water pressure, the influence of water pressure on the concrete strength was basically linear, the fitted equation of which is shown as equation (1).

Other research similar to the one in this study is Li's [13]. He studied the influence of water pressure, in the range of 0.5-2.5 MPa, on the strength and moisture content of concrete. Both $\mathrm{Li}$ and this paper designed experiments using the same test code, DL/T 5150-2001. Moreover, he considered the effect of strength grade, with specimens of two different standard strength grade which are referred to as L1 and L2, respectively, in this paper. Li's data are also depicted in Figure 3, illustrating the same pattern:

$$
D_{\mathrm{s}}=1-\frac{f_{\mathrm{c}}}{f_{\mathrm{c} 0}}=k_{1} P_{\mathrm{w}},
$$

where $D_{\mathrm{s}}$ is the damage in concrete caused by water pressure, defined as the reduction rate of strength, $f_{c}$ is the static compressive strength processed with water pressure, and $f_{\mathrm{c} 0}$ is the strength under no water pressure, in $\mathrm{MPa} . P_{\mathrm{w}}$ is the water pressure, in $\mathrm{MPa} . k_{1}$ is the parameter obtained by fitting, and the specific values are listed in Table 5.

In Table 5, A0-D0, A1-D1, and A2-D2 refer to the specimens tested in this research, which are cylinders in static compression, discs in static compression, and discs in dynamic compression, respectively. The design compressive strength of specimens $(150 \mathrm{~mm} \times 150 \mathrm{~mm} \times 150 \mathrm{~mm})$ was $40 \mathrm{MPa}$ with a measured strength of $45.35 \mathrm{MPa}$. L1 and L2 refer to specimens in Li's research [13], the design compressive strength was $15 \mathrm{MPa}$ and $20 \mathrm{MPa}$, while the tested strength of which was $16.90 \mathrm{MPa}$ and $26.7 \mathrm{MPa}$, respectively.

It could be observed in Table 5 that specimens with higher standard strength have lower reduction rate of strength. The relationship between $k_{1}$ and the measured compressive strength is illustrated in Figure 4 and fitted as equation (2). In that, the standard strength of materials has an impact on the damage degree of concrete:

$$
\begin{aligned}
& k_{1}=-1.5+196 \cdot f_{\mathrm{cu}}^{-1}, \\
& R^{2}=0.99 .
\end{aligned}
$$

In which, $f_{\mathrm{cu}}$ is the measured compressive strength of concrete, in MPa. 
TABLE 4: Static compressive strength of concrete under different water pressure/MPa (disc specimens).

\begin{tabular}{|c|c|c|c|c|c|c|}
\hline Serial number & Water pressure & Specimen 1 & Specimen 2 & Specimen 3 & Average & $D_{\mathrm{s}}$ \\
\hline A1 & 0 & 79.16 & 82.18 & 76.10 & 79.15 & 0 \\
\hline B1 & 1 & 78.86 & 77.45 & 84.31 & 80.21 & $7.1 \%$ \\
\hline $\mathrm{C} 1$ & 2 & 71.81 & 77.91 & 77.32 & 75.68 & $4.4 \%$ \\
\hline D1 & 4 & 68.82 & 70.67 & 69.86 & 69.78 & $11.8 \%$ \\
\hline
\end{tabular}

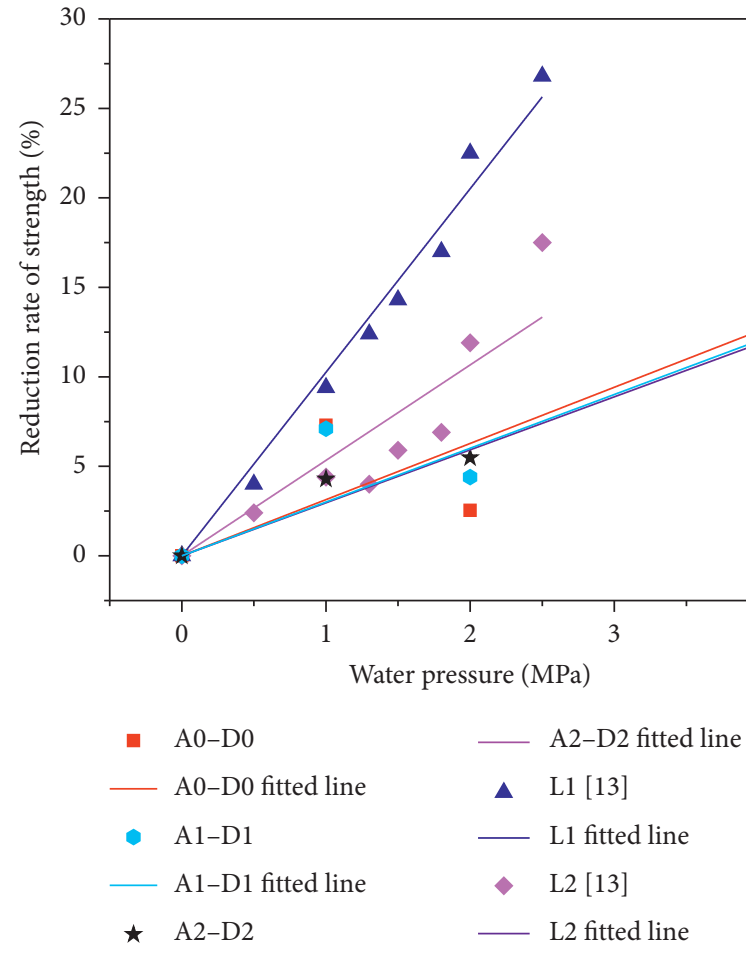

FIGURE 3: Effect of water pressure on the reduction rate of strength.

TABLE 5: Fitting parameters of the relationship between reduction rate of strength and water pressure.

\begin{tabular}{lccccc}
\hline Parameters & A0-D0 & A1-D1 & A2-D2 & L1 [13] & L2 [13] \\
\hline$k_{1}$ & 3.139 & 3.005 & 2.961 & 10.255 & 5.333 \\
$R^{2}$ & 0.87 & 0.91 & 0.99 & 0.99 & 0.96 \\
\hline
\end{tabular}

According to equation (1) and equation (2), the relationship among the strength of concrete, water pressure, and standard strength could be illustrated as follows:

$$
f_{\mathrm{c}}=f_{\mathrm{c} 0}\left(-1.5+196 f_{\mathrm{cu}}^{-1}\right) P_{\mathrm{w}} .
$$

The tested reduction rate and the calculated values according to equation (3) are demonstrated in Figure 5. The root-mean-square error (RMSE) of L1, L2, and A0-D0 was $1.20,2.27$, and 2.88 , respectively.

3.3. Dynamic Compressive Strength of Concrete Subject to Water Pressure. Dynamic strength of specimens showed a clear-cut lowering trend with increasing water pressure, which could be seen in Table 6 and Figure 6. As water pressure increased from $0 \mathrm{MPa}$ to $1 \mathrm{MPa}, 2 \mathrm{MPa}$, and $4 \mathrm{MPa}$, the average reduction rate of compressive strength was $4.30 \%, 5.38 \%$, and $11.73 \%$, in respective. The correlation between the rate of

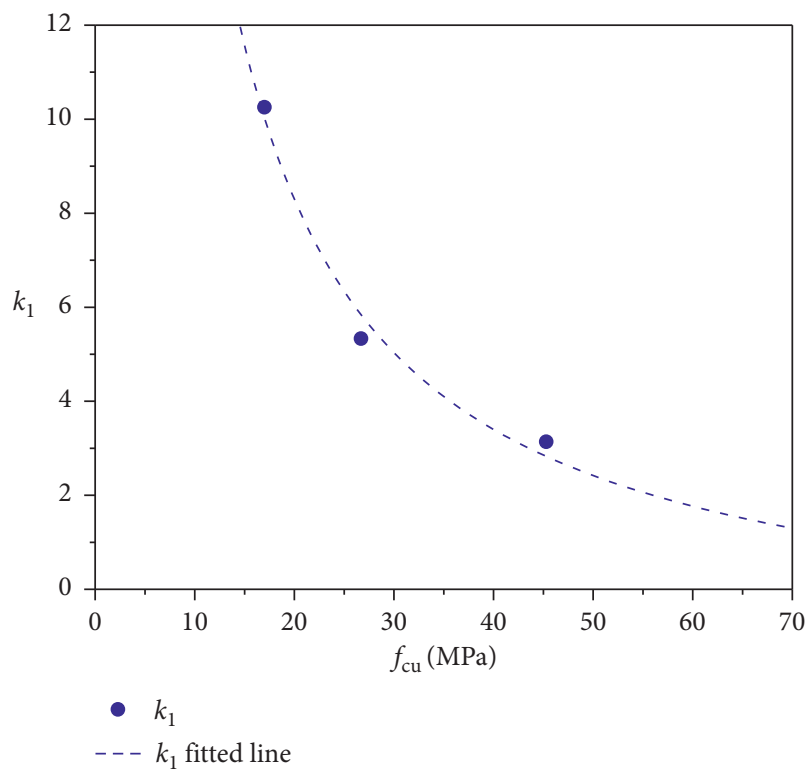

FIGURE 4: Influence of strength grade of concrete on the parameter $k_{1}$.

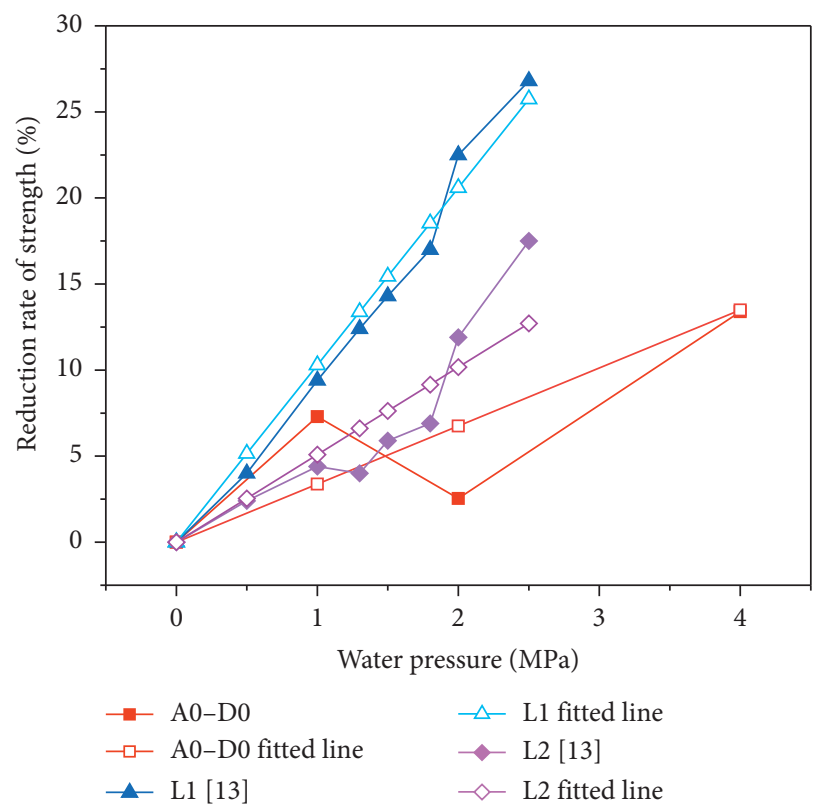

FIgURE 5: Calculated values of the static reduction rate of strength versus tested values.

dynamic strength loss and water pressure is nearly linearly almost the same as in the static state, as shown in Figure 3. In the SHPB test, the parameter $k_{1}$ according to equation (1) is 2.961, while the coefficient of correlation is 0.99 . 
TABle 6: Dynamic compressive strength of concrete under different water pressures (MPa).

\begin{tabular}{|c|c|c|c|c|c|c|}
\hline Serial number & Water pressure & Specimen 1 & Specimen 2 & Specimen 3 & Average & $D_{\mathrm{s}}$ \\
\hline $\mathrm{A} 2$ & 0 & 70.30 & 70.60 & 72.80 & 70.99 & 0 \\
\hline B2 & 1 & 68.36 & 72.79 & 62.67 & 67.94 & $4.3 \%$ \\
\hline $\mathrm{C} 2$ & 2 & 65.31 & 69.37 & 66.62 & 67.10 & $5.48 \%$ \\
\hline $\mathrm{D} 2$ & 4 & 58.33 & 66.80 & 62.85 & 62.66 & $11.73 \%$ \\
\hline
\end{tabular}

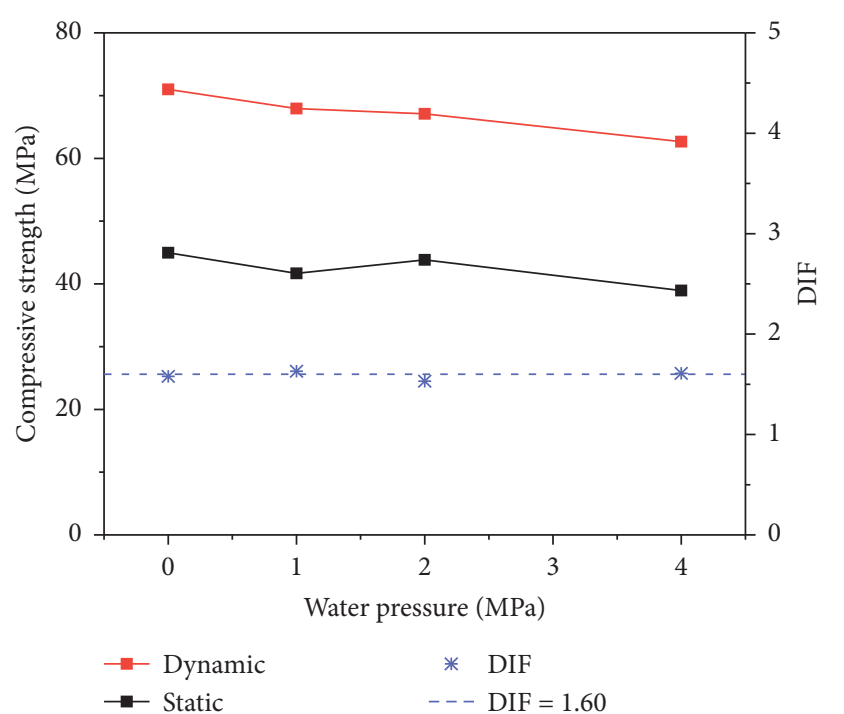

FIGURE 6: Influence of loading rate on compressive strength of concrete.

As displayed in Figure 6, the dynamic compressive strength of concrete was higher than the static strength under the same water pressure, illustrating a lucid strain rate effect. The dynamic increase factor (DIF), defined as the ratio of dynamic and static strength of specimens, demonstrates the changing pattern of compressive strength along with strain rate, in another word, the strain rate sensitivity. As test results shown, DIF were all in approximation to 1.60 under $0-4 \mathrm{MPa}$ water pressure. It could be concluded that under the influence of water pressure no more than $4 \mathrm{MPa}$, the dynamic increase factor of concrete is not sensitive to the change of water pressure.

3.4. Moisture Content. The specific measuring method of concrete moisture content is as follows. First, specimens were put into an oven set with $60^{\circ} \mathrm{C}$ for 48 hours. The weight of specimens was measured, both before and after drying. The moisture content of concrete, defined as the gap between two measurements compared with the value before drying, is illustrated as follows:

$$
\omega_{\mathrm{c}}=\frac{m_{\mathrm{w}}-m_{\mathrm{d}}}{m_{\mathrm{d}}} \times 100 \% .
$$

Here, $\omega_{\mathrm{c}}$ is the moisture content of the specimen (\%).$m_{\mathrm{w}}$ and $m_{\mathrm{d}}$ are the weight of the specimen measured before and after drying, in respective.

The results of the moisture test are shown in Table 7. For specimens processed by $0 \mathrm{MPa}, 1 \mathrm{MPa}, 2 \mathrm{MPa}$, and $4 \mathrm{MPa}$ water pressure, the average moisture content of which was $1.986 \%, 2.283 \%, 2.217 \%$, and $2.512 \%$, respectively. It consistently raised with the increment of water pressure. Before reaching $1 \mathrm{MPa}$ water pressure, the increasing speed of water
TABLE 7: Moisture content of concrete under different water pressure.

\begin{tabular}{cccccc}
\hline \multicolumn{2}{c}{ Water pressure $(\mathrm{MPa})$} & 0 & 1 & 2 & 4 \\
\hline & Specimen 1 & 1.884 & 2.284 & 2.410 & 2.558 \\
Moisture content (\%) & Specimen 2 & 2.203 & 2.311 & 2.157 & 2.356 \\
& Specimen 3 & 1.871 & 2.255 & 2.083 & 2.623 \\
Average & 1.986 & 2.283 & 2.217 & 2.512 \\
\hline
\end{tabular}

content was the fastest, which became slower afterward until $4 \mathrm{MPa}$ water pressure.

3.5. Relationship between the Increment of Moisture Content and the Reduction Rate of Strength. Based on connectivity with the outside, the pores in concrete are divided into connected pores and unconnected pores. When concrete is in the state of no water pressure, the free water only existed in the connected pores. However, with the effect of water pressure, the cell wall between the connected and unconnected pores is broken down by pressure, leading to penetration of free water into unconnected pores along with the accumulation of moisture content in concrete. The increment of moisture content and the deterioration of concrete (penetration of pore walls due to water pressure) is thus related.

Concrete specimens with three types of strength grades mentioned above were chosen to study the relationship between moisture content increment and water pressure, as depicted in Figure 7. The effect of water pressure on moisture content increment is presented as follows:

$$
\Delta \omega_{\mathrm{c}}=k_{2} P_{\mathrm{w}} .
$$

Here, $\Delta \omega_{c}$ is the increment of moisture content of the concrete specimen under different water pressure (\%), $k_{2}$ is the parameter obtained from fitting, and the value of which is listed in Table 8 .

It could be observed from Figure 7 that the increment of moisture content grew linearly with water pressure increase. The increase of moisture content of specimens with higher strength was smaller under the same water pressure. This could be attributed to the difference in their porosity, as it is lower if the strength of concrete is higher [27-29], and the cell wall between the connected and unconnected pores is thicker. It takes higher pressure to break down the pore walls of concrete with higher strength. In that, the strength of concrete has certain impact on the increment of water content, and the relationship between the parameter $\mathrm{k}_{2}$ and the compressive strength of concrete is presented as follows:

$$
k_{2}=6.05 \times 10^{4} f_{\mathrm{cu}}^{2}+0.020 f_{\mathrm{cu}}+0.464 .
$$




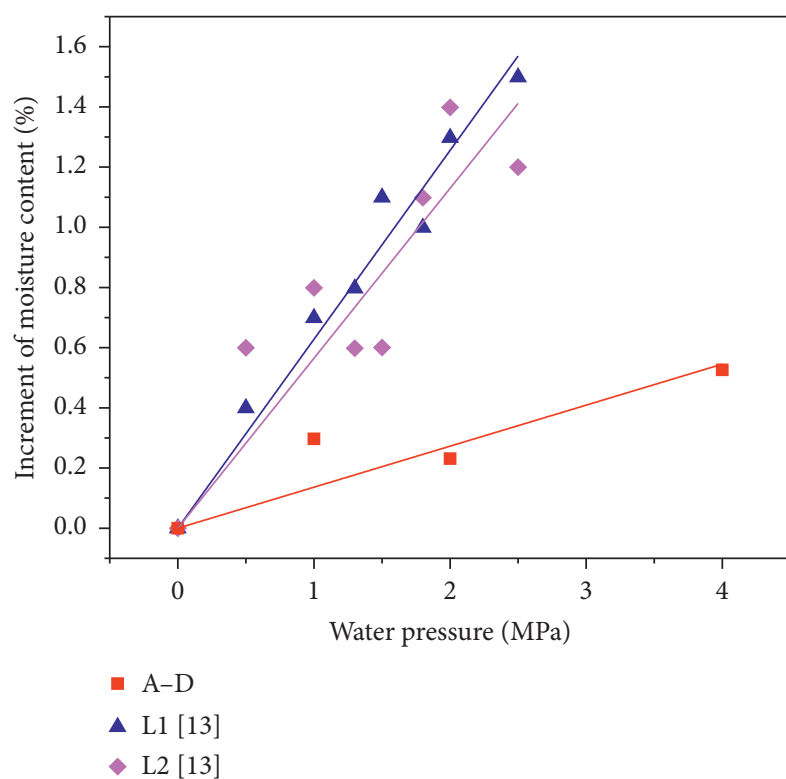

FIgURE 7: Increment of moisture content of specimens under different water pressure.

TABLE 8: Fitting parameter in the relationship between the moisture content increment and water pressure.

\begin{tabular}{lccc}
\hline Parameters & A-D & L1 [13] & L2 [13] \\
\hline$k_{2}$ & 0.136 & 0.628 & 0.565 \\
$R^{2}$ & 0.97 & 0.99 & 0.97 \\
\hline
\end{tabular}

Here, $f_{\mathrm{cu}}$ is the measured compressive strength of concrete, in MPa.

In combination of equations (3), (5), and (6), the reduction rate of strength could be illustrated as follows:

$$
D_{\mathrm{s}}=\frac{k_{1}}{k_{2}} \Delta \omega_{\mathrm{c}}=\frac{-1.5+196 \cdot f_{\mathrm{cu}}^{-1}}{6.05 \times 10^{4} f_{\mathrm{cu}}^{2}+0.020 f_{\mathrm{cu}}+0.464} \Delta \omega_{\mathrm{c}} .
$$

The calculated reduction rate of strength based on equation (7) is demonstrated in Figure 8, exhibiting a relatively close developing trend with experimental data overall. The RMSE of L1, L2, and A-D was 1.99, 3.06, and 1.55 , in respective.

Both static and dynamic compressive strength of concrete decreased as the increment of moisture content augmented, as shown in Figure 9. Their trend with the increase of moisture content was quite similar and synchronous. It could be concluded that the moisture content augmentation barely had any influence on DIF. The equation describing the dynamic compressive strength of water-pressurized concrete is as follows:

$$
f_{\mathrm{c}, \mathrm{d}}=f_{\mathrm{c} 0}\left(1-\frac{k_{1}}{k_{2}} \Delta \omega_{\mathrm{c}}\right)\left(\frac{\dot{\varepsilon}}{\dot{\varepsilon}_{0}}\right)^{k_{3}} .
$$

Here, $f_{c, d}$ is the dynamic compressive strength. $\dot{\varepsilon}$ and $\dot{\varepsilon_{0}}$ are the loading rate of the dynamic and static tests, the value

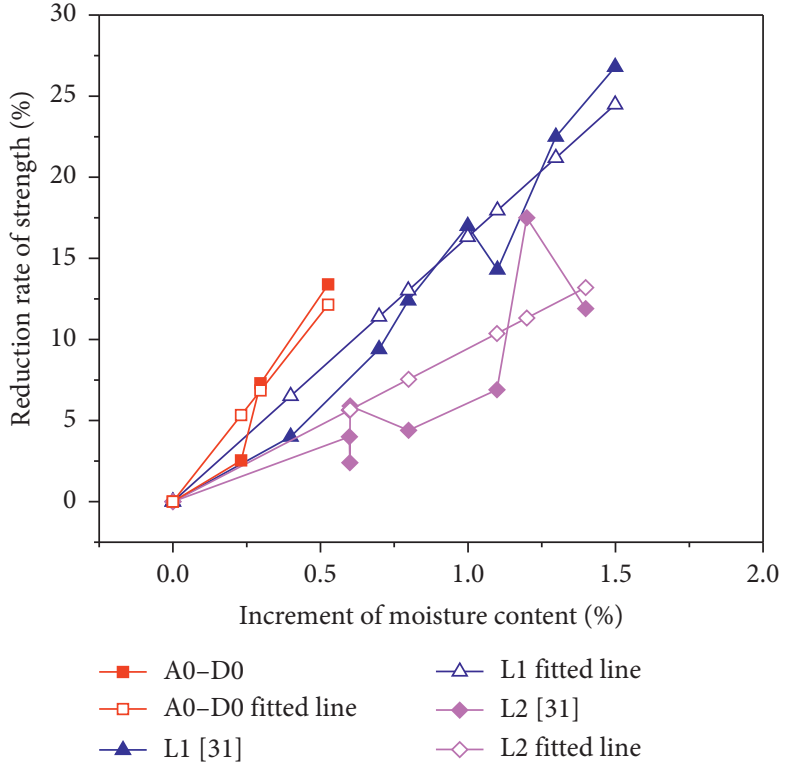

Figure 8: Influence of moisture content increment on static reduction rate of strength.

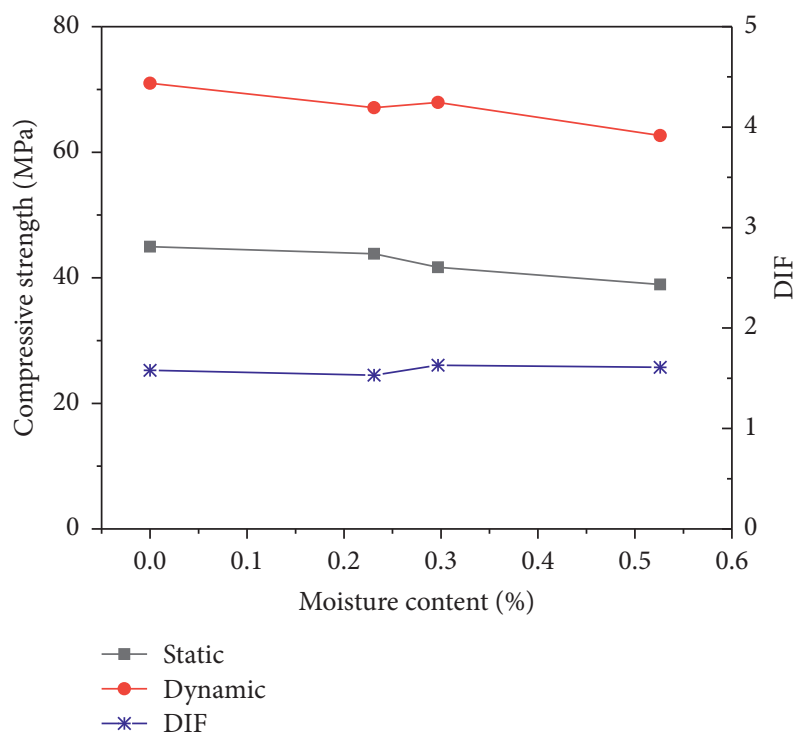

Figure 9: Effect of moisture content on the strength of concrete.

of which is $10^{2} / \mathrm{s}$ and $2.5 \times 10^{-5} / \mathrm{s}$, respectively, in this study. $k_{3}$, a parameter obtained by fitting, is $0.0309 . k_{1}$ and $k_{2}$ are demonstrated in equation (2) and equation (6), respectively.

\section{Conclusions}

In this paper, the influence of water pressure on concrete was studied by experiments. Both static and dynamic compression tests were carried out on specimens subjected to different water pressure environments, investigating the influence of water pressure on static and dynamic strength of concrete. The conclusions can be drawn as follows: 
(1) High water pressure causes inevitable damage to concrete. Under pressure between 0 and $4 \mathrm{MPa}$, the static and dynamic compressive strength of concrete decreased along with the increase of water pressure. The reduction rate of strength reached up to $13.4 \%$ at maximum while the water pressure was $4 \mathrm{MPa}$. Moreover, the strength grade of concrete has a specific effect on the reduction rate of compressive strength. Concrete with lower initial compressive strength is more vulnerable to damage. Based on water pressure and standard compressive strength of concrete, an equation calculating the reduction rate of compressive strength was provided.

(2) The moisture of concrete increases almost linearly along with water pressure, which would eventually result in the reduction of strength. The increment of moisture content augmented slower under the same testing condition if the initial compressive strength of concrete is relatively higher. An equation, formulated on water pressure and increment of moisture content, has been established to predict the reduction rate of compressive strength.

(3) The dynamic compressive strength of concrete deteriorates with the increase of water pressure. The dynamic compressive strength was higher than the static for specimens under the same water pressure, reflecting an evident strain rate effect. With the same increment of moisture content in concrete, the reduction rate of static and dynamic strength was nearly the same. Moreover, almost no effect had the increment of moisture content on the DIF of concrete. Based on the increment of moisture content due to water pressure, a predictive equation for the dynamic strength of concrete was built.

For further work, we will study the effect of water pressure on pore size distribution of concrete. The relationship among water pressure, strength damage, and pore size distribution will be addressed. Also, how mineral admixtures change the performance of concrete under water pressure will be surveyed. In addition, the seepage-stress coupling will be applied into the damage mechanism analysis.

\section{Data Availability}

All data used to support the findings of this study are included in this article.

\section{Conflicts of Interest}

The authors declare that there are no conflicts of interest regarding the publication of this paper.

\section{Acknowledgments}

This research was funded by the National Key Research and Development Program of China, under grant no. 2017YFC0404902, and the National Natural Science
Foundation of China, under grant no. 51479048. The authors gratefully acknowledge the financial supports.

\section{References}

[1] H. Chen, "On the obstacles and way to assess the seismic catastrophe for high arch dams," Science in China Series E: Technological Sciences, vol. 50, no. S1, pp. 11-19, 2007.

[2] P. H. Bischoff and S. H. Perry, "Compressive behaviour of concrete at high strain rates," Materials and Structures, vol. 24, no. 6, pp. 425-450, 1991.

[3] Q. M. Li and H. Meng, "About the dynamic strength enhancement of concrete-like materials in a split Hopkinson pressure bar test," International Journal of Solids and Structures, vol. 40, no. 2, pp. 343-360, 2003.

[4] S. Popovics, "Effect of curing method and final moisture condition on compressive strength of concrete," American Concrete Institute (ACI) Journal Proceedings, vol. 83, pp. 650-657, 1986.

[5] F. M. Bartlett and J. G. MacGregor, "Effect of moisture condition on concrete core strengths," American Concrete Institute Materials Journal, vol. 91, no. 3, pp. 227-236, 1994.

[6] G. Zhang, X. Li, and Z. Li, "Experimental study on static mechanical properties and moisture contents of concrete under water environment," Sustainability, vol. 11, no. 10, p. 2962, 2019.

[7] P. Forquin, K. Safa, and G. Gary, "Influence of free water on the quasi-static and dynamic strength of concrete in confined compression tests," Cement and Concrete Research, vol. 40, no. 2, pp. 321-333, 2010.

[8] H. W. Reinhardt, P. Rossi, and J. G. M. van Mier, "Joint investigation of concrete at high rates of loading," Materials and Structures, vol. 23, no. 3, pp. 213-216, 1990.

[9] C. A. Ross, D. M. Jerome, J. W. Tedesco, and M. L. Hughes, "Moisture and strain rate effects on concrete strength," American Concrete Institute Materials Journal, vol. 93, no. 3, pp. 293-300, 1996.

[10] S. Wu, X. Chen, and J. Zhou, "Influence of strain rate and water content on mechanical behavior of dam concrete," Construction and Building Materials, vol. 36, pp. 448-457, 2012.

[11] J. Zhou, X. Chen, L. Wu, and X. Kan, "Influence of free water content on the compressive mechanical behaviour of cement mortar under high strain rate," Sadhana, vol. 36, no. 3, pp. 357-369, 2011.

[12] N. Clayton, "Concrete strength loss from water pressurisation," Proceedings of Materials and Concrete, vol. 86, pp. 177-186, 1986.

[13] Z. Li and S. Du, "Experimental study on mechanical properties of concrete due to high seepage pore water pressure," Engineering. Mechanics, vol. 28, pp. 72-77, 2011, in Chinese.

[14] Q. Wang, Y. Liu, and G. Peng, "Effect of water pressure on mechanical behavior of concrete under dynamic compression state," Construction and Building Materials, vol. 125, pp. 501-509, 2016.

[15] G. Van Der Wegen, J. Bijen, and R. Van Selst, "Behaviour of concrete affected by sea-water under high pressure," Materials and Structures, vol. 26, no. 9, pp. 549-556, 1993.

[16] L. Bjerkeli, J. J. Jensen, and R. Lenschow, "Strain development and static compressive strength of concrete exposed to water pressure loading," American Concrete Institute (ACI) Structural Journal, vol. 90, pp. 310-315, 1993.

[17] J. E. Butler, "The influence of pore pressure upon concrete," Magazine of Concrete Research, vol. 33, no. 114, pp. 3-17, 1981. 
[18] B. Bary, J.-P. Bournazel, and E. Bourdarot, "Poro-damage approach applied to hydro-fracture analysis of concrete," Journal of Engineering Mechanics, vol. 126, no. 9, pp. 937-943, 2002.

[19] P. Rossi, J. G. M. Van Mier, C. Boulay, and F. Le Maou, "The dynamic behaviour of concrete: influence of free water," Materials and Structures, vol. 25, no. 9, pp. 509-514, 1992.

[20] D. Zheng and Q. Li, "An explanation for rate effect of concrete strength based on fracture toughness including free water viscosity," Engineering Fracture Mechanics, vol. 71, no. 16-17, pp. 2319-2327, 2004.

[21] H. Oshita and T.-A. Tanabe, "Water migration phenomenon in concrete in postpeak region," Journal of Engineering Mechanics, vol. 126, no. 6, pp. 573-581, 2000.

[22] J. Shen and Q. Xu, "Effect of moisture content and porosity on compressive strength of concrete during drying at $105^{\circ} \mathrm{C}$," Construction and Building Materials, vol. 195, pp. 19-27, 2019.

[23] E. Ryshkewitch, "Compression strength of porous sintered alumina and zirconia," Journal of the American Ceramic Society, vol. 36, no. 2, pp. 65-68, 1953.

[24] J. Zhou and Y. Liang, "Effect of water on the dynamic tensile mechanical properties of calcium silicate hydrate: based on molecular dynamics simulation," Materials, vol. 12, no. 17, p. 2837, 2019.

[25] GB175-2009, Common Portland Cement, China Standard Press, Beijing, China, 2009, in Chinese.

[26] DL/T 5150-2001, Test Code for Hydraulic Concrete, China Electric Power Press, Beijing, China, 2002, in Chinese.

[27] R. Kumar and B. Bhattacharjee, "Porosity, pore size distribution and in situ strength of concrete," Cement and Concrete Research, vol. 33, no. 1, pp. 155-164, 2003.

[28] X. Chen and S. Wu, "Influence of water-to-cement ratio and curing period on pore structure of cement mortar," Construction and Building Materials, vol. 38, pp. 804-812, 2013.

[29] Y. Malecot, L. Zingg, M. Briffaut, and J. Baroth, "Influence of free water on concrete triaxial behavior: the effect of porosity," Cement and Concrete Research, vol. 120, pp. 207-216, 2019. 